\title{
ANALISIS PERKEMBANGAN KEPRIBADIAN TOKOH SHOUYA ISHIDA DALAM ANIME KOE NO KATACHI
}

\author{
I.A.P.A Purnamasari ${ }^{1}$, R.A. Pinka ${ }^{2}$, Hardianto ${ }^{3}$ \\ ${ }^{123}$ Jurusan Bahasa Asing, Universitas Pendidikan Ganesha, Singaraja \\ e-mail: ayu.aryasti@undiksha.ac.id, rahila@undiksha.ac.id, hardianto@undiksha.ac.id
}

\begin{abstract}
Abstrak
Penelitian ini bertujuan untuk mendeskripsikan perkembangan kepribadian pada tokoh utama yang bernama Shouya Ishida dalam Anime berjudul Koe No Katachi. Penelitian ini menggunakan metode deskriptif dan studi pustaka. Pembahasan dan kegiatan analisis dalam penelitian ini menggunakan pendekatan teori kepribadian Carl Gustav Jung. Tujuan dari penelitian ini, yaitu untuk mendeskripsikan perkembangan kepribadian tokoh Shouya Ishida dalam Anime Koe No Katachi. Hasil penelitian menunjukkan bahwa kepribadian Shouya Ishida pada masa anak-anak berdasarkan teori psikoanalisis Carl Gustav Jung dari aspek gabungan sikap dan fungsi, Shouya Ishida pada masa kecil memiliki tipe kepribadian ektroversi-pengindraan, karena terdapat kepribadian yang jahil dan suka bergaul. Sedangkan, kepribadian Shouya Ishida pada masa remaja memiliki tipe kepribadian introversipengindraan, karena terdapat kepribadian yang suka menyendiri. Shouya Ishida mengalami perkembangan kepribadian dari ektraversi menjadi introversi ditinjau dari kedua aspek yaitu mekanistik dan sinkronisitas, karena dipengaruhi oleh peristiwa pada masa lalu dan peristiwa psikis yang terjadi secara bersamaan.
\end{abstract}

Kata kunci : perkembangan kepribadian, Shouya Ishida, Carl Gustav Jung

\section{Abstract}

The aim of this study was to describe the personality development of the main character named Shouya Ishida in the Anime entitled Koe No Katachi. This research used descriptive method and literature study. The discussion and analysis activities in this research use Carl Gustav Jung's personality theory approach. The purpose of this study was to describe the personality development of the character Shouya Ishida in the Koe No Katachi Anime. The results showed that Shouya Ishida's personality as a child was based on Carl Gustav Jung's psychoanalytic theory from the combined aspect of attitude and function, Shouya Ishida in childhood had an ectroversion-sensing personality type, because there was a mischievous and sociable personality. Meanwhile, Shouya Ishida's personality in adolescence had an introversion-sensing personality type, because there was a solitary personality. Shouya Ishida experienced personality development from extraversion to introversion in terms of both mechanistic and synchronic aspects, because it was influenced by events in the past and psychic events that occurred simultaneously.

Keywords: personality development, Shouya Ishida, Carl Gustav Jung

\section{Pendahuluan}

Koe no Katachi merupakan anime movie karya Yoshitoki Ouima. Anime ini menceritakan tentang pengalaman hidup seorang tokoh utama yang bernama Shouya Ishida yang menindas tokoh perempuan yang bernama Nishimiya Shouko pada masa SD bersama teman-teman di kelasnya. Nishimiya Shouko ditindas oleh Shouya Ishida dan teman-teman sekelasnya karena Nishimiya Shouko yang menyandang penyakit tunarungu (kurang berfungsinya indera pendengaran) sampai Nishimiya Shouko dipindahkan ke sekolah lain karena penindasan yangdilakukan Shouya Ishida dan teman-temannya terlalu berlebihan.

Saat kepala sekolah turun tangan untuk mencari dalang dari penindasannya hanya Shouya Ishida yang disalahkan dan teman-teman sekelasnya ikut menyalahkan Shouya Ishida yang akhirnya Shouya Ishida balik ditindas teman-temannya sampai lulus SMP. Dulu Shouya 
Ishida yang memiliki sifat yang periang, senang bermain dengan teman-temannya, dan menyukai sesuatu yang menantang pada masa remajanya Shouya Ishida menjadi orang yang sangat tertutup, penyendiri, membenci orang lain termasuk juga membenci dirinya sendiri sampai-sampai Shouya Ishida berencana mengahiri hidupnya dengan bunuh diri.

Hal yang menarik perhatian kami terhadap tokoh Shouya Ishida yaitu peristiwa perubahan kepribadian yang dialami oleh tokoh tersebut, terutama menceritakan dampak dari pembulianpada anak-anak. Maka dari itu, dari ketertarikan terhadap tokoh Shouya Ishida, perlu menganalisis lebih lanjut tokoh tersebut untuk meneliti tentang perkembangan kepribadian dan mencari tahu aspek perkembangan kepribadian apa yang mempengaruhi tokoh Shouya Ishida sehingga kepribadiannya dapat berubah dengan cara mencari tahu kepribadian Shouya Ishida pada masa kecil dan masa remajanya terlebih dahulu dengan menggunakan teori kepribadian Carl Gustav Jung dengan judul "Analisis Perkembangan Kepribadian Tokoh Shouya Ishida dalam Anime Koe No Katachi". Agar penelitian yang dilakukan terarah dan mendapatkan hasil yang diharapkan, maka harus ditetapkan rumusan masalah. Adapun rumusan masalah pada penelitian ini adalah bagaimana perkembangan kepribadian tokoh Shouya Ishida dalam Anime Koe No Katachi. Dengan ditentukannya rumusan masalah maka dapat diketahui tujuan dari penelitian, yaitu untuk mendeskripsikan perkembangan kepribadian tokoh Shouya Ishida dalam Anime Koe No Katachi.

Pembahasan dan kegiatan analisis dalam penelitian ini menggunakan pendekatan teori kepribadian Carl Gustav Jung. Semasa hidupnya, manusia pasti melalui berbagai kejadian dalam hidupnya. Kejadian-kejadian tersebut dapat mempengaruhi seseorang sehingga kepribadiannya dapat berubah sebagaimana kejadian yang dialami sehingga dapat mempengaruhinya. Dalam hal ini, Jung (dalam Alwisol 2009:53-54) menjelaskan bahwa perkembangan kepribadian dipengaruhi oleh tiga aspek. Berikut adalah ketiga aspek tersebut.

a. Mekanistik (Mechanistic)

Jung mengangkat teori mekanistik dari pandangan Freud yang bersifat mekanistik atau kausalistik, menurutnya semua peristiwa disebabkan oleh sesuatu yang terjadi pada masa lalu.

b. Purposif (Purposive)

Jung mengedepankan pandangan purposif atau teleologik, yang menjelaskan kejadian sekarang ditentukan oleh masa depan atau tujuan. Jung yakin pada pandangan bahwa pemahaman terhadap kepribadian tidak hanya ditentukan dari masa lalu tetapi juga ditentukan oleh masa depan.

c. Sinkronisitas (Synchronicity)

Menurut Jung, peristiwa psikis tidak selalu dapat dijelaskan dengan prinsip sebab akibat. Duaperistiwa psikis yang terjadi secara bersamaan dan tampak saling berhubungan, yang satu tidak menjadi penyebab dari yang lain, karena keduanya tidak dapat ditunjukan mana yang masa lalu dan mana yang masa depan.

Adapun manfaat dari penelitian ini adalah diharapkan mampu menambah pengetahuan terkaitpsikologis, khususnya perkembangan kepribadian dengan teori kepribadian oleh Carl Gustav Jung.

\section{Metode Penelitian}

Metode Penelitian yang dilakukan berupa metode deskriptif yaitu, penelitian yang dilaksanakan untuk menganalisis prilaku sosial secara spesifik yang terjadi didalam konteks sosial yang dialami. Menurut Sugiyono (2009:29) metode deskriptif adalah suatu metode yang berfungsi untuk mendeskripsikan atau memberi gambaran terhadap objek yang diteliti melalui data atau sampel yang telah terkumpul, sebagaimana adanya tanpa melakukan analisis dan membuat kesimpulan yang berlaku untuk umum. Dalam metode ini data yang diperoleh yaitu narasi secara detail yang menjelaskan objek penelitian. Dalam mengumpulkan data kami 
menggunakan studi pustaka, yaitu menonton film secara keseluruhan dari anime "Koe No Katachi", lalu mengelompokan fenomena yang berkaitan dengan pokok permasalahan yang dialami oleh objek penelitian. Objek yang kami amati berupa dialog, ekspresi tokoh Shouya Ishida dan pendekatan visual karakter. Dengan menggunakan metode deskripsi, penulis menggunakan fakta yang telah dideskripsikan dalam film "Koe no katachi" untuk dijadikan sebagai sumber data dalam penelitian. Hal ini dilakukan agar dapat menghasilkan hasil yang sesuai untuk menjawab masalah penelitian yang berupa hal yang memengaruhi tokoh Shouya Ishida mengalami depresi.

\section{Hasil dan Pembahasan}

Menurut Jung (dalam Alwisol 2009:47) kombinasi sikap dan fungsi ini untuk mendeskripsikan tipe-tipe kepribadian manusia. Dari dua aspek ini dimana akan dikombinasikan sehingga dapat diketahui tipe kepribadian manusia dari kedua aspek sikap dan fungsi yang paling menonjol sehingga dapat diketahui bahwa terdapat delapan tipe kepribadian yaitu introversi-pikiran, ektraversi-pikiran, introversi-perasaan, ekstraversi perasaan, introversi-pengindraan, ekstraversi pengindraan, introversi-intuisi, dan ekstraversiintuisi. Berikut adalah pembahasan tentang tipe kepribadian, dan aspek perkembangan kepribadian tokoh Shouya Ishida.

3.1 Kepribadian tokoh Shouya Ishida pada masa anak-anak a. Jahil

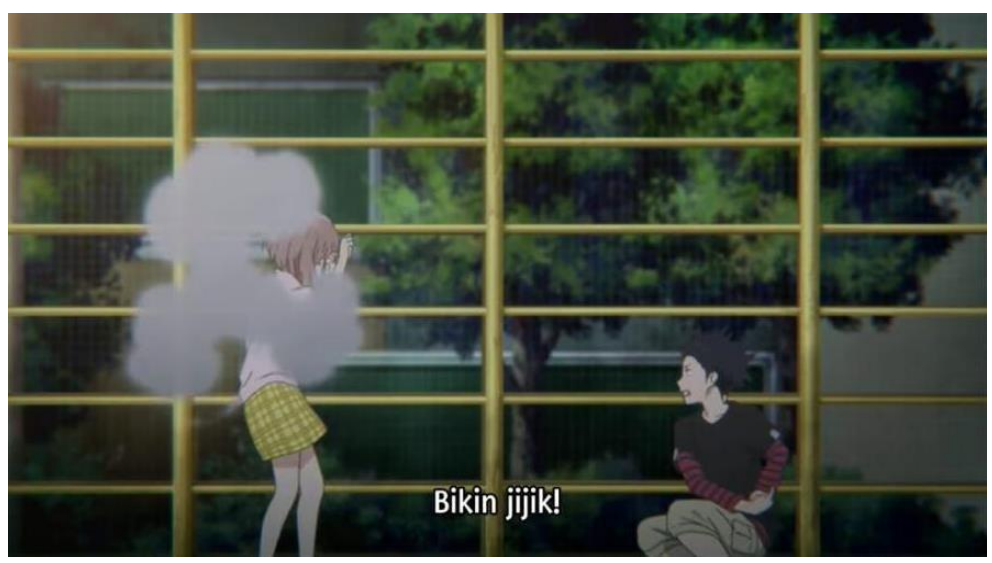

Gambar 1

Pada kutipan (1) di menit ke 10:15 diambil dengan menggunakan teknik menangkap gambar. Pada gambar ini, Shouya Ishida menjahili Nishimiya dengan mengambil pasir dan melemparkan pasir kehadapan Nishimiya. Pada awalnya Nishimiya hanya ingin mengajak Ishida untuk menjadi teman, namun karena Ishida tidak ingin menjadi teman Nishimiya akhirnya ia melemparkan pasir kehadapan Nishimiya. Pada kutipan (1) bisa disimpulkan bahwa Shouya Ishida memiliki sifat yang jahil. Alasannya karena ia tidak ingin berteman dengan Nishimiya, ia melemparkan pasir kehadapannya. 


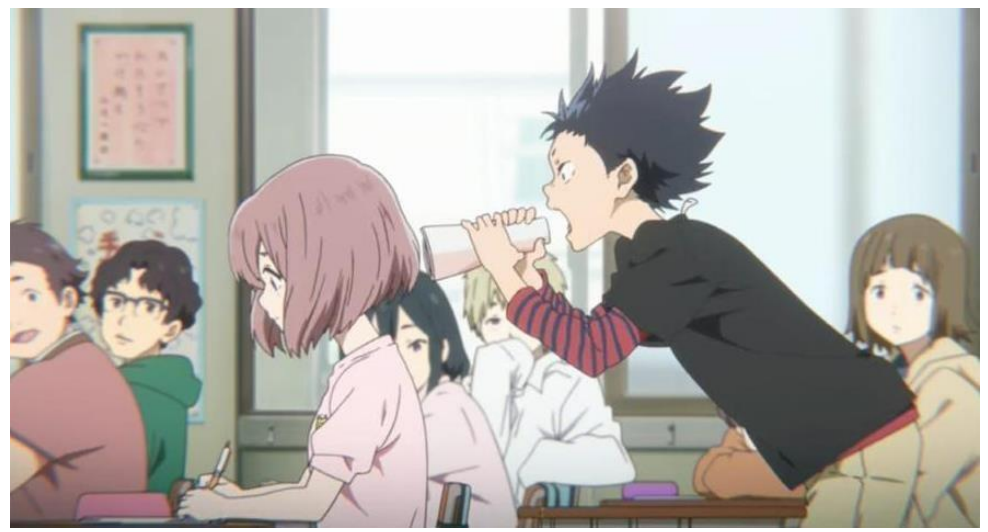

Gambar 2

Pada kutipan (2) di menit 14:06 diambil dengan menggunakan teknik menangkap gambar. Pada gambar ini, Shouya Ishida menjahili Nishimiya lagi dengan berteriak dari belakang Nishimiya. Karena hal itu, Nishimiya dan seisi kelas terkejut dengan kelakukan Shouya Ishida. Pada kutipan (2) bisa disimpulkan bahwa Shouya Ishida memiliki sifat yang jahil. Alasannya karena, ia selalu menjahili Nishimiya.

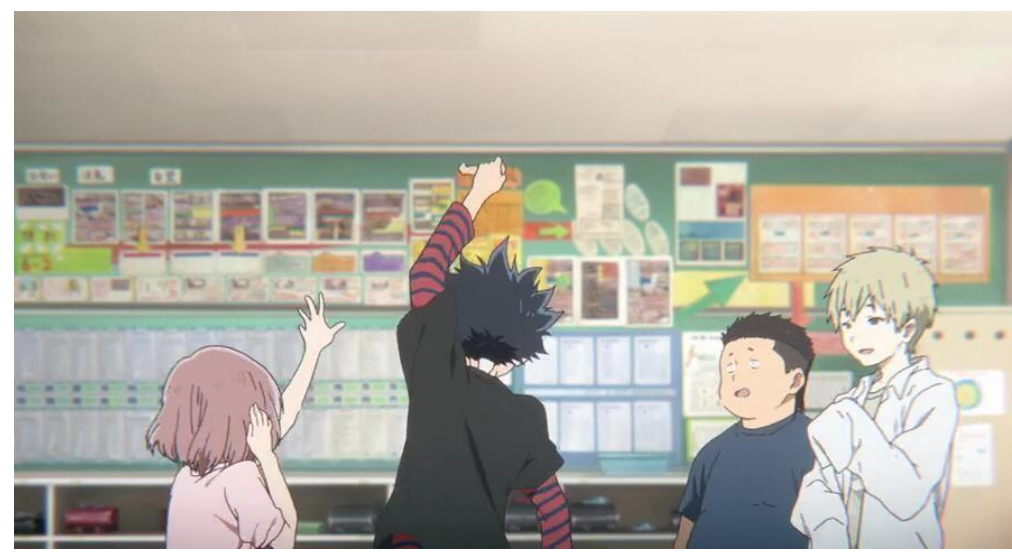

Gambar 3

Pada kutipan (3) di menit 14:13 diambil dengan menggunakan teknik menangkap gambar. Pada gambar ini, kejahilan Shouya Ishida pada Nishimiya terus berlanjut. Pada gambar ini, Shouya Ishida mengambil alat bantu pendengaran yang dimiliki oleh Nishimiya. Pada kutipan (3) bisa disimpulkan bahwa, Shouya Ishida memiliki sifat yang jahil, dan secara terus-menerus menjahili Nishimiya. 
b. Suka bergaul

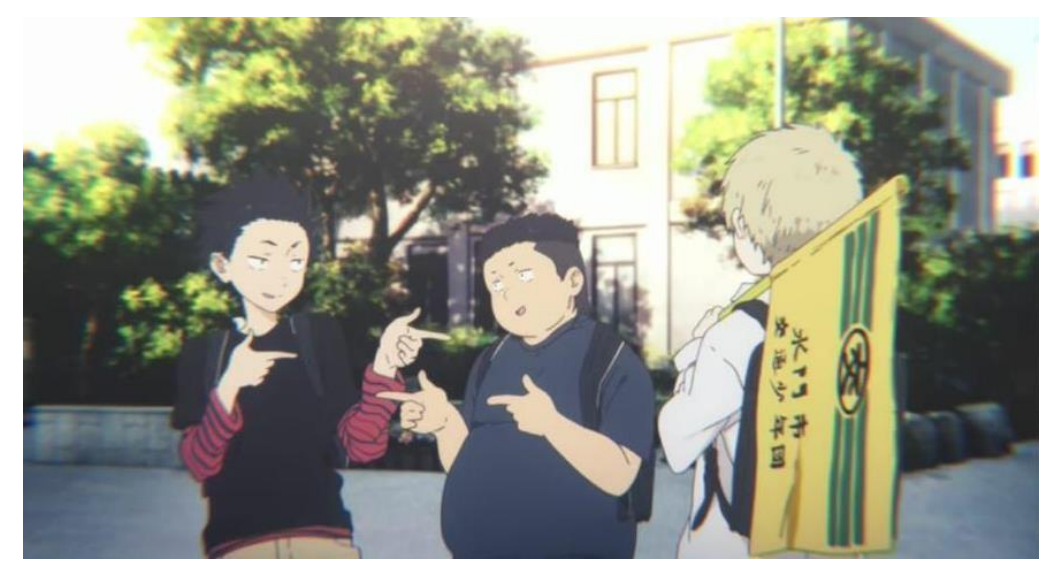

Gambar 4

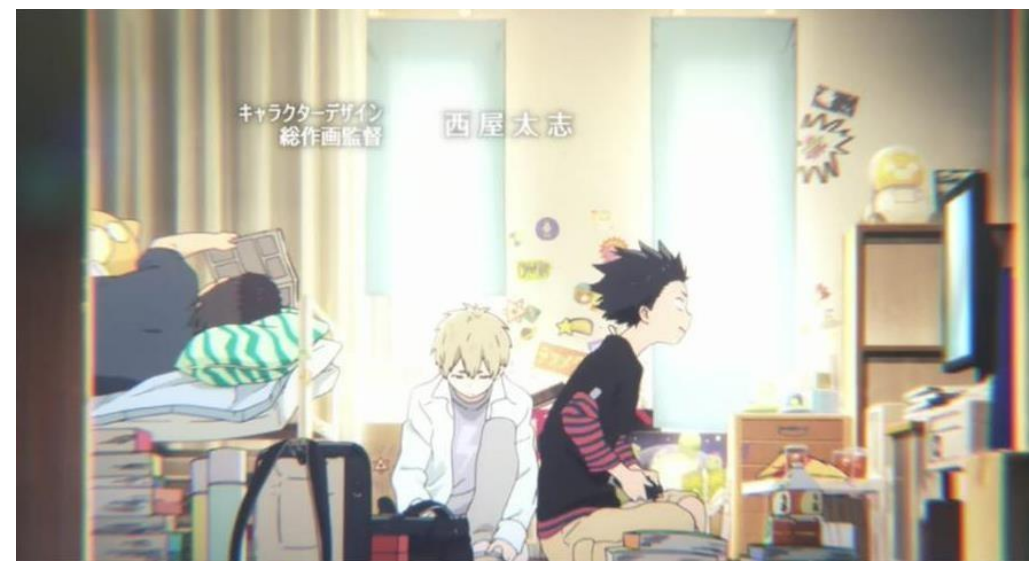

Gambar 5

Pada kutipan (1) dan (2) di menit 03:05 dan 02:53 diambil dengan menggunakan teknik menangkap gambar. Pada gambar ini, terlihat Shouya Ishida dengan teman-temannya bercanda, dan saling bertukar salam. Selain itu, Shouya Ishida dan teman-temannya menghabiskan waktu untuk bermain game dan membaca komik. Pada kutipan (1) ini dapat disimpulkan bahwa, Shouya Ishida suka bergaul dengan teman-temannya. 
3.2 Kepribadian tokoh Shouya Ishida pada masa remaja

a. Penyendiri

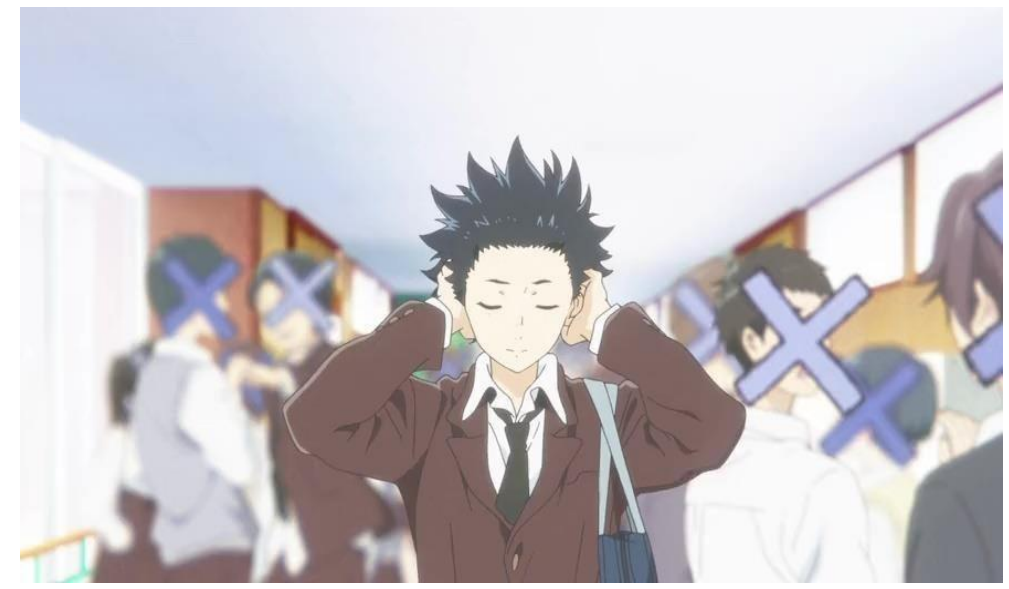

Gambar 6

Kutipan (1) dimenit ke 30.25 diambil menggunakan sosial menangkap gambar. Pada gambar ini, Shouya Ishida mulai menghindari kerumunan sosial dan menutup telinga karena kebisingan sekitar di sekolahnya

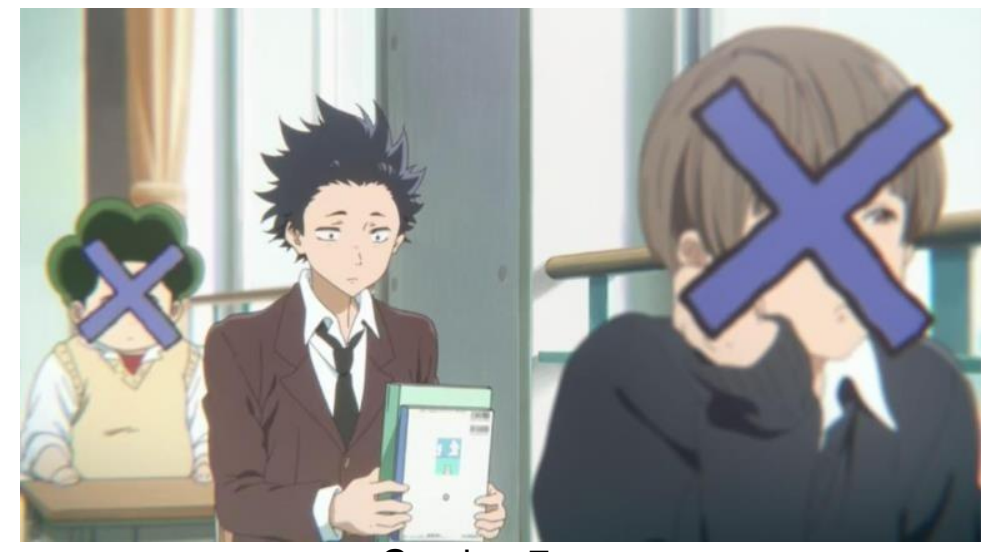

Gambar 7

Kutipan (2) dimenit ke 30.32 diambil menggunakan teknik menangkap gambar. Pada gambar ini, Shouya Ishida menyendiri di dalam kelasnya karena dari pemikiran Ishida, dia takut orang-orang berbicara mengenai dirinya yang pernah menjahili Shouko Nishimiya hingga pindah sekolah. 


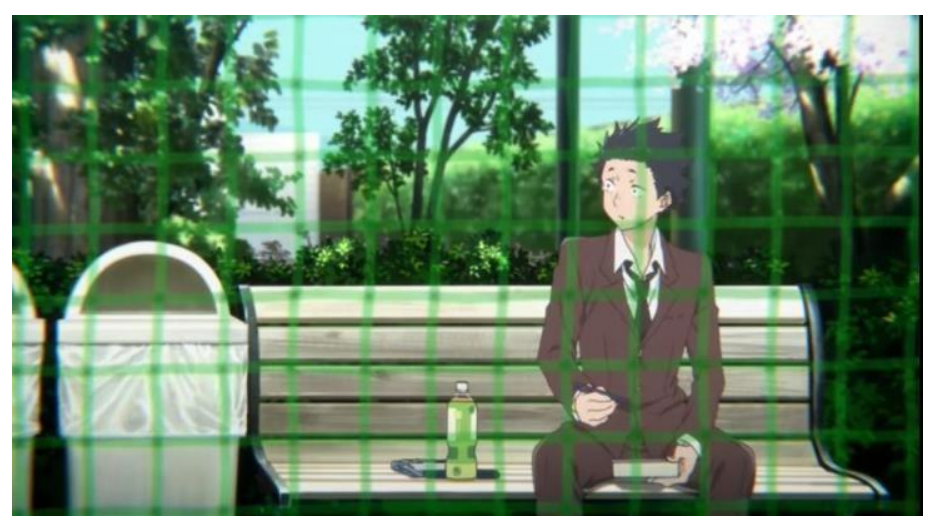

Gambar 8

Kutipan (3) dimenit ke 32.10 diambil menggunakan teknik menangkap gambar. Pada gambar ini, Shouya Ishida menyendiri memakan bekalnya pada saat jam istirahat.

\subsection{Aspek yang mempengaruhi perkembangan kepribadian Shouya Ishida}

a. Pengaruh aspek mekanistik

Aspek mekanistik merupakan semua peristiwa yang disebabkan oleh sesuatu yang terjadi pada masa lalu. Ishida mengalami perkembangan kepribadian dari tipe kepribadian ekstraversi-pegindraan menjadi tipe introversi-pengindraan melalui peristiwa yang terjadi pada masa lalunya. Dari penjelasan tersebut dapat disimpulkan bahwa perkembangan kepribadian Shouya Ishida dipengaruhi oleh aspek mekanistik. Kutipan dibawah ini adalah penggambaran bahwa perkembangan kepribadian Shouya Ishida dipengaruhi dari aspek mekanistik.

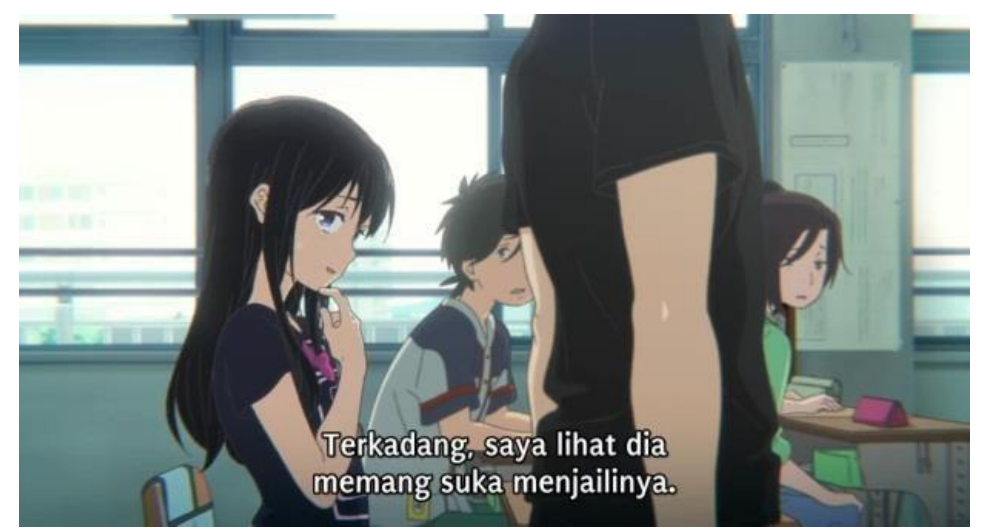

Gambar 9 


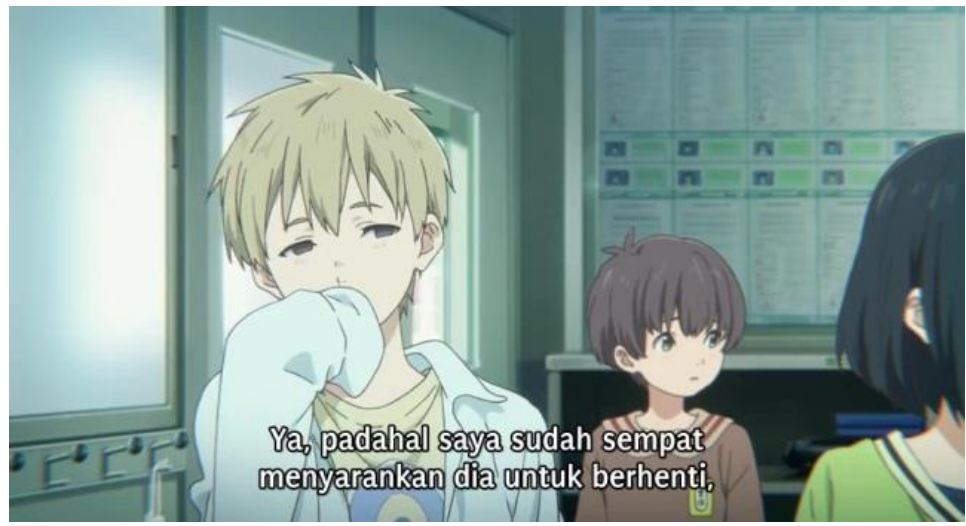

\section{Gambar 10}

Kutipan (1) Adegan berikut diambil menggunakan teknik menangkap gambar dan dialog tokoh lain. Ueno berkata bahwa dia melihat Ishida suka menjahili (Nishimiya), dan Shimada berkata bahwa dirinya sudah menyarankan dia (Ishida) untuk berhenti.

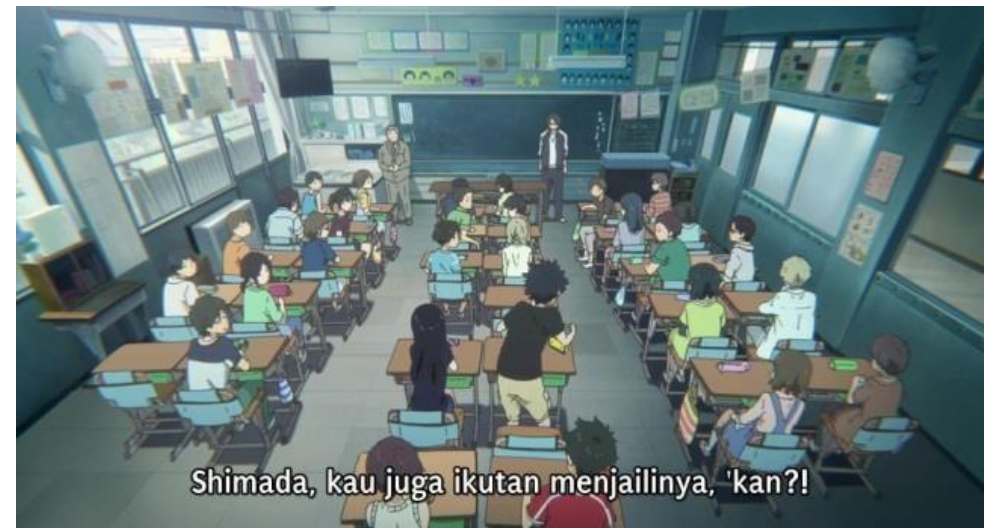

Gambar 11

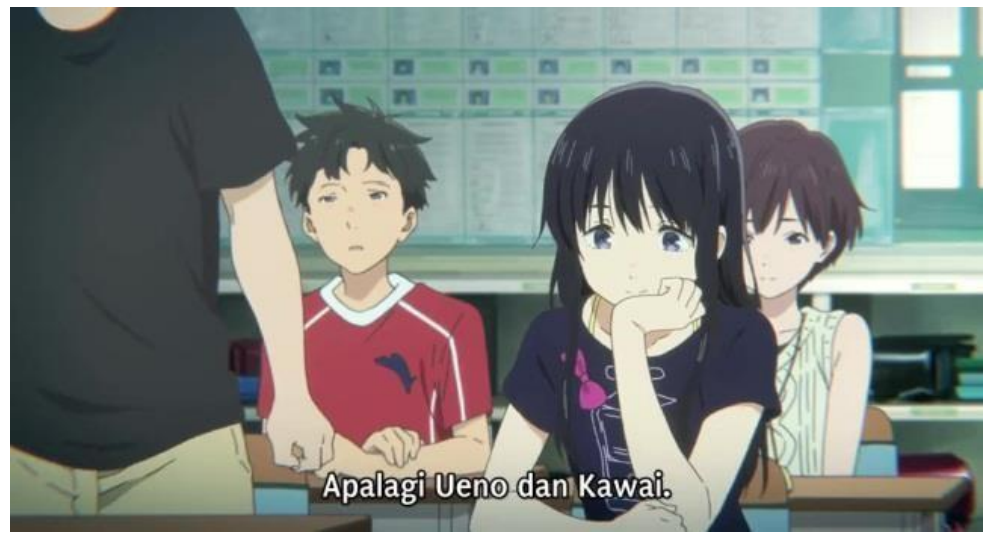

Gambar 12

Kutipan (2) Adegan berikut diambil menggunakan teknik menangkap gambar dan dialog tokoh. Ishida merasa tidak terima jika dirinya disalahkan sendiri atas 
pembullyan yang terjadi kepada Nishimiya. Dia berkata bahwa Shimada juga ikut menjahili, terlebih Ueno dan Kawai.

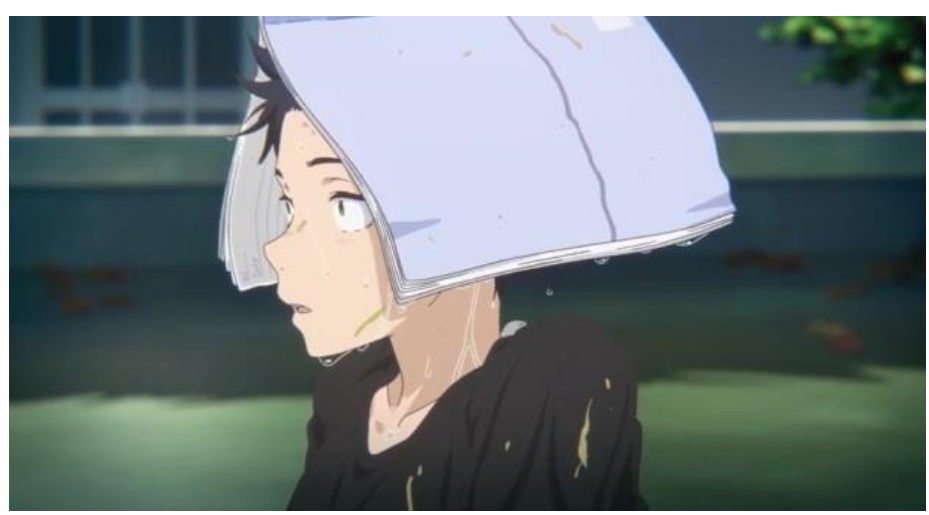

Gambar 13

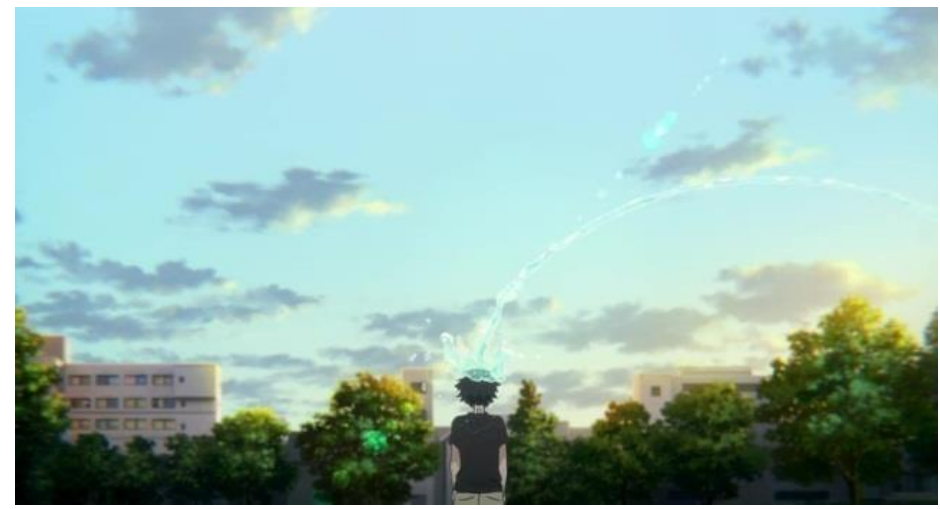

Gambar 14

Kutipan (3) Adegan berikut diambil menggunakan teknik menangkap gambar. Pada gambar tersebut, Ishida dibully oleh teman-temannya akibat ucapannya dalam adegan pada kutipan kedua.

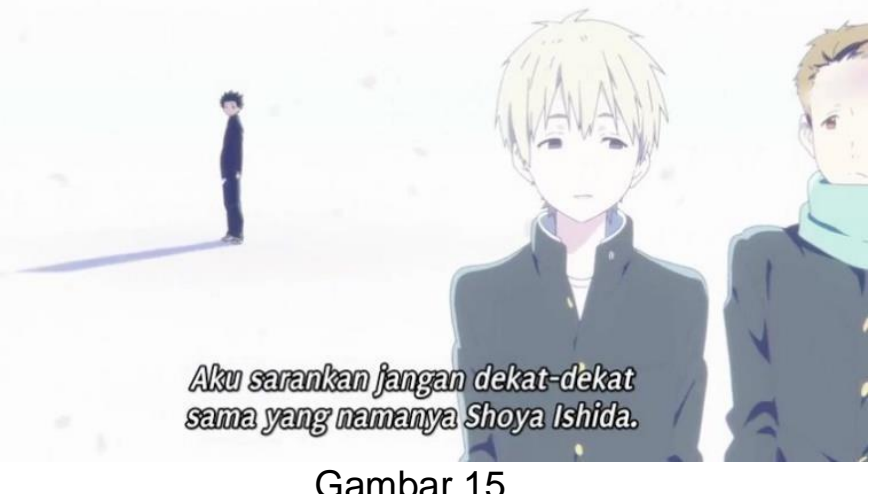

Kutipan (4) di menit ke 29.24 diambil menggunakan teknik menangkap gambar dan dialog tokoh lain. Pada gambar tersebut, Shimada selaku teman Ishida semasa SD menjelekkan Ishida dan menggiring opini teman-teman barunya di SMP untuk menjauhi Ishida karena tukang jahil akut. 


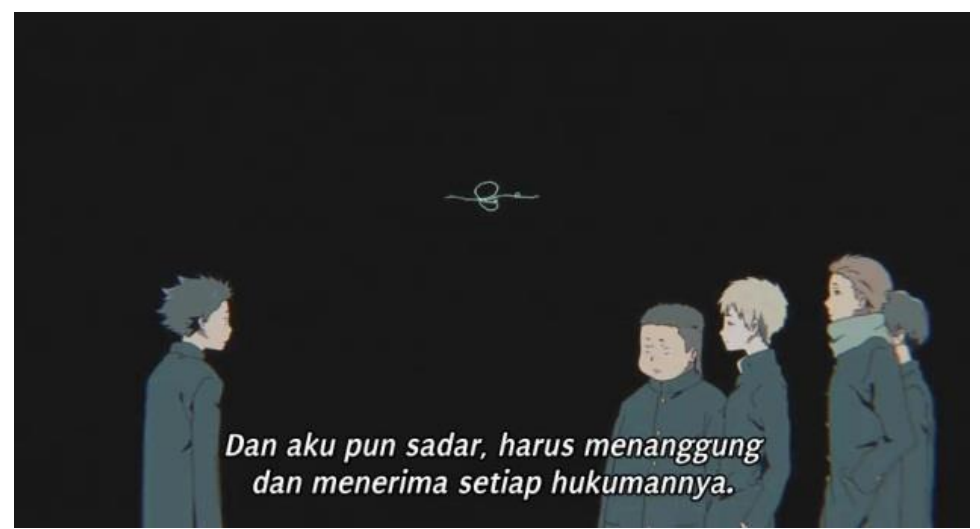

Gambar 16

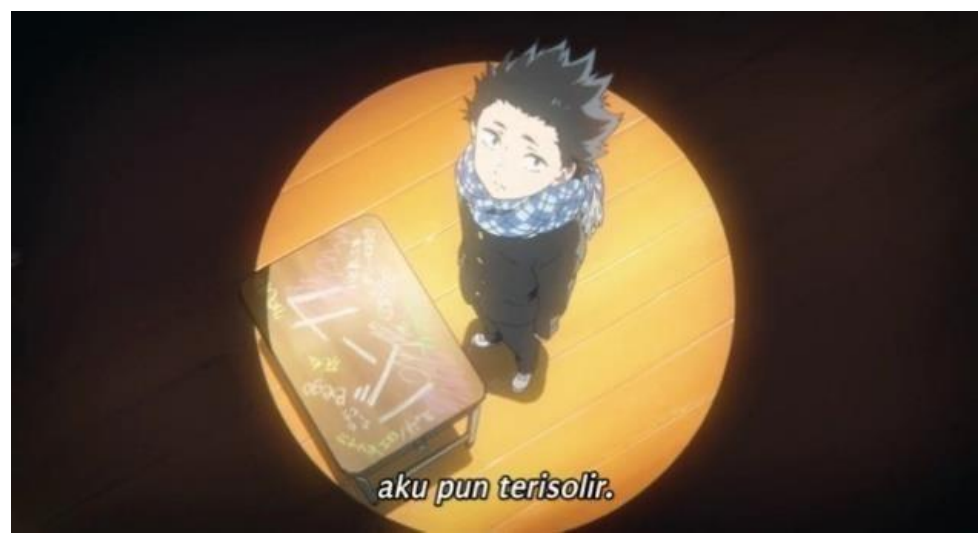

Gambar 17

Kutipan (5) di menit ke 29.45 dan 29.48 diambil menggunakan teknik menangkap gambar dan dialog tokoh. Pada gambar tersebut, Ishida menyadari perbuatannya dan harus menanggung serta menerima setiap hukumannya, hingga dia pun terisolir.

b. Purposif (Purposive)

Pada film anime "Koe No Katachi" tidak ditemukan aspek purposif yang dimuat. Aspek purposif merupakan semua peristiwa saat ini yang ditentukan oleh masa depan atau tujuan. Dalam anime ini, hanya dipengaruhi oleh peristiwa pada masa lalu, tidak ditemukan pemahaman terhadap kepribadian yang ditentukan oleh masa depan.

c. Pengaruh Aspek Sinkronisitas

Selain aspek mekanistik yang mempengaruhi perkembangan kepribadian Shouya Ishida, dia juga dipengaruhi oleh aspek sinkronisitas. Shouya Ishida sempat mengalami peristiwa psikis yang terjadi secara bersamaan dan tampak saling berhubungan, dalam artian kejadian masa lalu dan rencana masa depan Shouya Ishida mempengaruhi perkembangan kepribadiannya. Berikut adalah kutipan yang menjelaskan bahwa Shouya Ishida dipengaruhi oleh aspek sinkronisitas. 


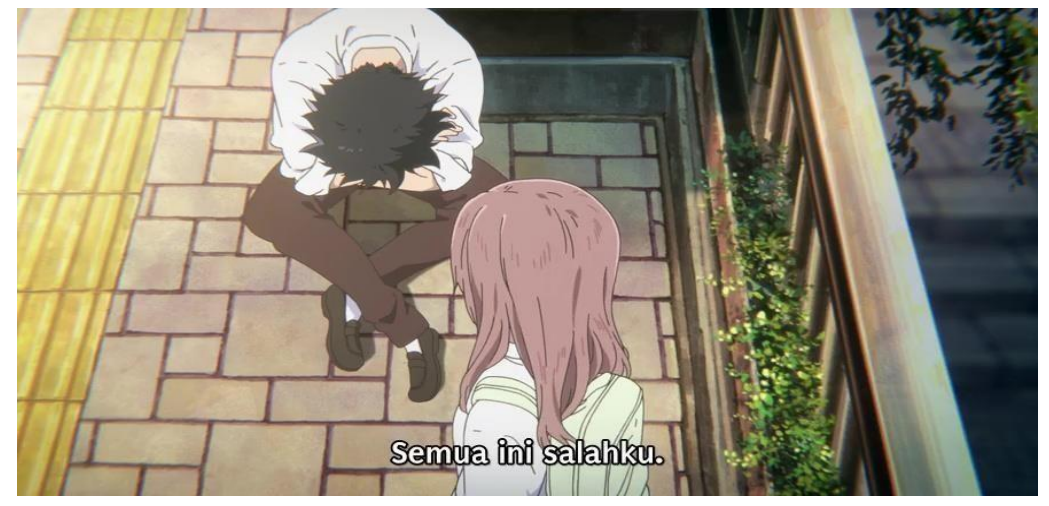

Gambar 18

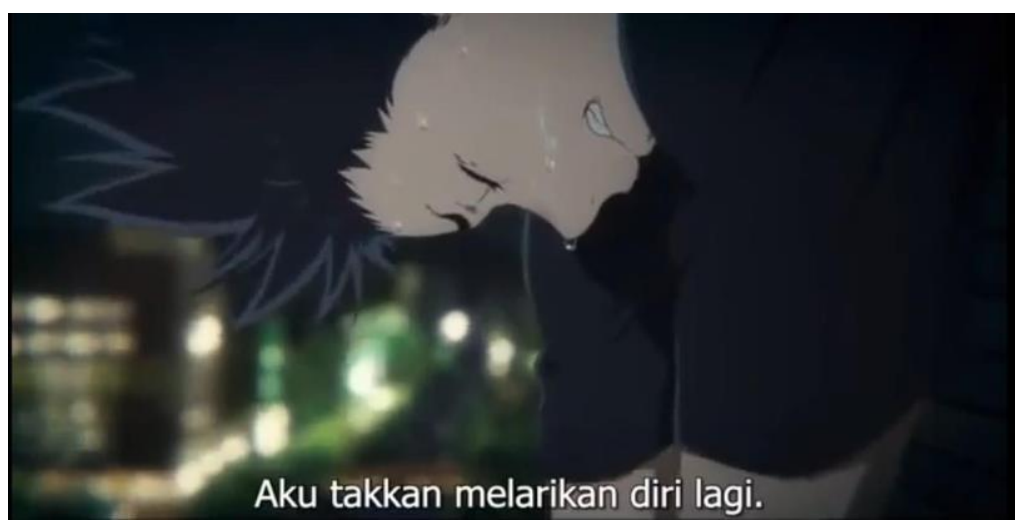

Gambar 19

Kutipan (1) dimenit ke 01.22.43 diambil menggunakan teknik menangkap gambar. Pada gambar ini, Ishida menyadari pembulian tersebut karena dia dan pasrah atas semua kesalahannya.

Kutipan (2) dimenit ke 01.39.20 diambil menggunakan teknik menangkap gambar. Pada gambar ini, Ishida meminta kepada Tuhan untuk memberinya kekuatan agar bisa menjadi orang yang lebih baik lagi.

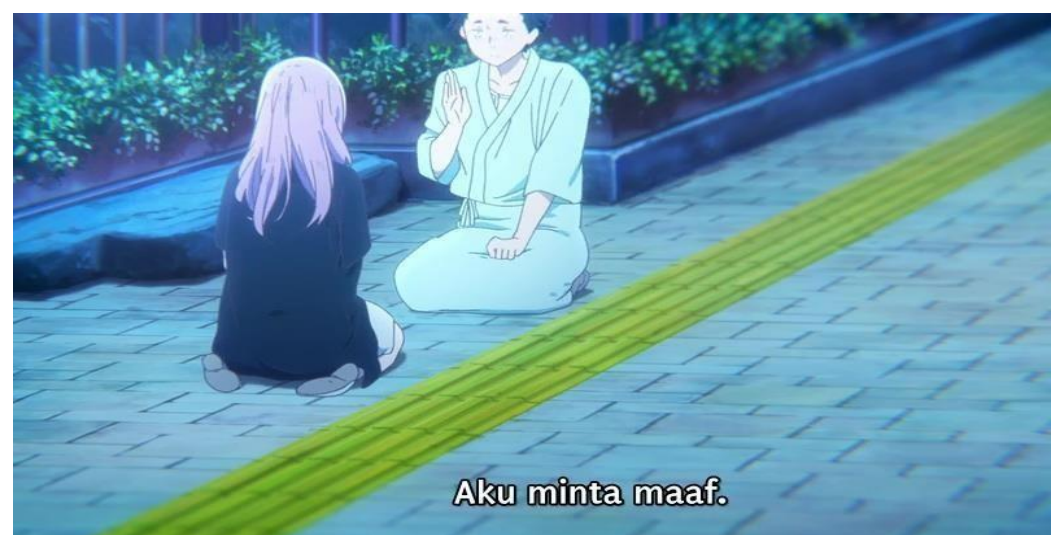

Gambar 20 
Kutipan (3) dimenit ke 01.52.03 diambil menggunakan teknik menangkap gambar. Pada gambar ini, Ishida meminta maaf dengan tulus kepada Nishimiya atas perbuatannya terdahulu.

\section{Kesimpulan}

Dari uraian di atas dapat disimpulkan bahwa kepribadian Shouya Ishida pada masa anak-anak berdasarkan teori psikoanalisis Carl Gustav Jung dari aspek gabungan sikap dan fungsi, Shouya Ishida pada masa kecil memiliki tipe kepribadian ektroversi-pengindraan, karena terdapat kepribadian yang jahil dan suka bergaul. Sedangkan, kepribadian Shouya Ishida pada masa remaja memiliki tipe kepribadian introversi-pengindraan, karena terdapat kepribadian yang suka menyendiri. Shouya Ishida mengalami perkembangan kepribadian dari ektraversi menjadi introversi ditinjau dari kedua aspek yaitu mekanistik dan sinkronisitas, karena dipengaruhi oleh peristiwa pada masa lalu dan peristiwa psikis yang terjadi secara bersamaan (masa lalu dan masa depan).

\section{Daftar Pustaka}

Haryanti, M.E. 2020. "Kepribadian Tokoh Koichi dan Ryunosuke Dalam Film Kiseki Karya Hirokazu Koreeda (Kajian Psikologi Sastra)". Semarang: Universitas Diponegoro. Hal: 41-42.

Shabrina, A.W. 2019. "Kepribadian Tokoh Jinta Yadomi Dalam Anime Anohana Karya Mari Okada Menurut Teori Jung". Semarang: Universitas Diponegoro. Hal: 41- 43.

Dayyan, M.N. 2020. "Tipe Arketipe Pada Tokoh Utama Nakitai, Watashi Wa Neko O Kaburu (Kajian Psikologi Analitis)”. Semarang: Universitas Diponegoro. Hal: 43-45

Syawali, N. 2020. "Kepribadian Tokoh Sakura Dalam Anime Kimi No Suizou Wo Tabetai (Kimisui) Karya Yoru Sumino (Kajian Psikoanalisis)". Semarang: Universitas Diponegoro. Hal: 30-33

Maulana, D.Y.D. 2017. "Analisis Kepribadian Tokoh Yuki Dan Ame Dalam Anime Ookami Kodomo No Ame To Yuki Karya Mamoru Hosoda Kajian Psikologi Sastra". Semarang: Universitas Diponegoro. Hal: 32-34

Tiofanny, S., Antartika, I.K., \& Sadyana, I.W. 2017. "Analisis Kepribadian Tokoh Yuko Dalam Cerpen Shanghai Nite Karya Koike Mariko Ditinjau Dari Psikoanalisis SigmundFreud". Singaraja: Universitas Pendidikan Ganesha.

Sumber belajar Vocsten Malang. Psikologi Kepribadian: Psikoanalitik. Diakses pada 2 Juli 2021, dari laman Sumber Belajar: https://sumberbelajarvocstenmlg.wordpress.com/kompetensi-guru/kompetensikepribadian/pengembangan-kepribadian-bab-2/

Perkembangan Kepribadian Menurut Pandangan Carl Gustav Jung. Diakses pada 2 Juli 2021 , dari laman Wordpress: https://ifanblogfree.wordpress.com/2011/07/25/perkembangan-kepribadian-menurutpandangan-carl-gustav-jung/ 